\title{
Teacher Support as a Moderator of Behavioral Outcomes for Youth Exposed to Stressful Life Events
}

\author{
Rebekah S. Huber, ${ }^{1}$ Sarah K. Sifers, ${ }^{2}$ Daniel Houlihan, ${ }^{2}$ and Rachel Youngblom ${ }^{2}$ \\ ${ }^{1}$ University of Utah, USA \\ ${ }^{2}$ Minnesota State University, USA \\ Correspondence should be addressed to Daniel Houlihan, daniel.houlihan@mnsu.edu
}

Received 21 March 2012; Revised 2 October 2012; Accepted 2 October 2012

Academic Editor: Eric Z. F. Liu

Copyright ( $) 2012$ Rebekah S. Huber et al. This is an open access article distributed under the Creative Commons Attribution License, which permits unrestricted use, distribution, and reproduction in any medium, provided the original work is properly cited.

\begin{abstract}
The present study examined the relationship between teacher support, life stress, and behavioral outcomes in 103 youth. Participants completed questionnaires regarding life events, social support, personality, and behavior. Moderated regression analyses were conducted using youth perceptions of teacher support and negative life events to predict externalizing and internalizing problems. Results revealed a significant interaction between teacher support and life stress, indicating teacher support successfully moderated the effect of stress on externalizing problems. Main effects for life stress were consistent with previous literature suggesting that higher amounts of stress predict greater externalizing and internalizing problems. Implications for teacher support are discussed.
\end{abstract}

\section{Introduction}

Children and adolescents endure different types of stress throughout development. A great deal of literature has focused on the stressors that children and adolescents experience and the effects of those stressors [1-4]. Children experience both acute and chronic stress [3,9]. Stressors can combine to produce synergistic effects, and a single source may affect more than one process in an individual. Furthermore, the same stressor can produce completely different outcomes in individuals [6].

Despite such complexity, there is consensus that most stressors have a negative impact on child and adolescent development [1, 3, 7-9]. Different types of stressors place children and adolescents at risk for varying negative outcomes. Research focused on the effects of different childhood stressors has evidenced an increased risk for maladaptive behavior [9] and psychological distress [3, 9]. Children who experience chronic stressors may exhibit heightened levels of risky behaviors such as early sexual activity, drug and alcohol abuse [6], suicide [10], and lower achievement in school and dropout [11]. The occurrence of chronic stress also can make children more susceptible to developing psychopathology, is correlated with depression, anxiety, schizophrenia [5], and learning disabilities [12].

1.1. Externalizing and Internalizing Problems. Negative emotional and behavioral outcomes that result from stress may be classified into different categories based on how the behavior presents itself. Aggression, hyperactivity, and conduct problems are easily observable, outwardly directed behaviors that can be defined as externalizing problems; whereas distress that is inwardly directed and not marked by acting outward or disturbing others, such as anxiety, depression, sense of inadequacy, and somatization are considered internalizing problems [4]. The current study seeks to focus on internalizing and externalizing problems in regard to stress and the negative emotional and behavioral outcomes in youth.

Despite the many adverse outcomes associated with stressors, some children exhibit resilience. The literature on resilience has proliferated over the past three decades, spotlighting children who have been referred to as "invincible," "invulnerable," and "superkids" [13-16]. Children who are stress-resilient do not possess superpowers, nor do they avoid 
the most negative outcomes associated with risk due to stressors. Instead, they have an adequate amount of adaptation in the face of adversity [12]. Stress-resilient children can be described as both being exposed to persistent or intense life stressors and being able to maintain competence in the presence of such troubling events [14].

Research has identified specific protective factors called protective mechanisms that reduce the effects of risk factors that would normally lead to negative outcomes and foster resilience in children [12,17-19]. The risk of emotional and behavioral maladjustment associated with stress can be lessened by protective mechanisms [20, 21]. Protective factors that buffer the effects of stress fall into three categories: (a) individual personality characteristics, (b) family environment, and (c) support from sources outside of the family $[2,19]$. Individual personality characteristics include traits such as intelligence and social competence. Family environment consists of family composition/structure and emotional support within the family. Resources outside the family include peers, teachers, and school and community involvement. This study will focus on support from outside the family, specifically, teacher support.

1.2. Nonfamilial Social Support. Proposed models and theories have been developed to explain how peers and adults outside of the family can serve protective roles [22, 23]. Ensel and Lin examined six models of the stress process to determine the causal relationship between stressors, resources, and distress. The study found that resources in the social environment significantly reduce psychological symptoms and mediate the effects of social stressors on psychological distress [22]. Another suggested theory of social support and resilience to stress is Lazarus and Folkman's Social Support Theory. It states that, (a) individuals can utilize stress mediators to their benefit in the presence of stress, and (b) individuals are more resistant to the adverse effects of stress based on the availability and utilization of a stress mediator. Peers, teachers, and other role models can serve as stress mediators.

Research on social environment and childhood stress has examined sources of support [24], the size and quality of social networks [25], and the effects of social support on competence, behavior, and psychopathology [26]. Many studies have focused primarily on peer support and friendship (c.f. $[24,27,28]$ ).

Conversely, some research has given increased attention to adults outside of the family who can serve as stress moderators (c.f. $[29,30])$. A role model outside of the family allows children to identify with an adult whom they respect, look up to, and admire. Teachers not only promote academic success, but they also serve as positive role models of personal identification for children. Research has shown that teachers have been the most frequently reported positive role model outside of the family [11].

1.3. Teacher Support. Social support from teachers has been shown to facilitate positive outcomes for children faced with risk [31-35]. The literature on social support from teachers toward interactions with students has reported care and concern [33, 36], empathy, trust, and assistance [35, 37], and respect and fairness [38]. Support from teachers in past research has generally been reported from the student's perspective. Thus, teacher support was defined in the current study as an amalgamation of teacher care, fairness, empathy, helping, challenging, and respect toward students that were measured from the youth's perspective.

Recent developmental and educational literature has focused specifically on components of the teacher-student relationship and its effects on children and the classroom [35, 39-41]. Teacher-student relationships have been shown to provide care, nurturing, and a means of adaptation for youth $[40,42]$. A positive teacher-student relationship can aid in the transition through school, lessen risk for problem behaviors, influence social competency with peers, and increase performance on schoolwork [35, 43].

Theoretical views of the teacher-student relationship stem from developmental, social, ecological, and systems approaches that see the relationship as part of larger system (e.g., classrooms), and as an interaction of social, environmental, and relational contexts. These theorists are concerned with how the relationship is maintained and how it affects child development. Much research on the teacher-student relationship examined the relationship from different perspectives using various methods in multiple contexts $[39,40,43]$. The teacher-student relationship has been measured from the child, teacher, and parent perspective [43]. Studies have also looked at the relationship objectively by observing the teacher and student interacting within different contexts of the classroom $[41,43]$.

1.4. Educational Resilience. When students succeed academically, despite exposure to adverse life circumstances, this is termed educational resilience [44]. A variety of elements in classrooms, students, teachers, and schools have been evaluated for their role in educational resilience. Educational resilience has proven to be complex and not one personality characteristic or individual has shown to be responsible for the result [45]. Rather, a combination of how a student interacts with resources in the environment can change the trajectory and cause a student to thrive academically [46].

Educational resilience research indicates that teachers are able to promote academic achievement and overall educational success in the presence of stressors [29, 34]. Studentteacher relationships can increase academic achievement, decrease the risk of dropout, and lower the risk of students engaging in negative behaviors at school [29, 33]. Research on educational resilience and teacher support has focused mainly on background characteristics of students [29, 32], student-teacher relationships [29, 32, 33], and strategies implemented by teachers $[32,33,47]$.

Children from backgrounds with low socioeconomic status, family conflict, relocation, divorce, violence, and ethnic diversity have been examined for educational resilience. Research has shown that teachers can encourage educational resilience for children with conflict in their family environment. Crosnoe and Elder [29] studied close 
relationships between friends, siblings, and teachers for youth in problematic family environments. The study found that emotional support provided by teachers through a close relationship served as an arena for comfort and promoted educational resilience [29]. Teachers can also facilitate educational resilience for youth in disadvantaged homes and neighborhoods [32, 34]. Nettles and colleagues [34] found that a supportive relationship with a teacher was beneficial to academic performance for students exposed to violence. Additionally, teacher-student relationships built on caring was shown to moderate stress due to financial hardship [32].

Research on educational resilience has identified qualities of teachers and strategies in the classroom for bolstering educational resilience in at-risk youth [32, 33, 47, 48]. One quantitative and two qualitative studies by Muller et al. [33] found that teachers fostered educational resilience by developing a cooperative relationship and displaying care. Muller et al. found that students performed better on standardized math exams when teachers displayed interest, care, praise, and when they expected success and listened to students. Furthermore, McClendon [47] implemented a year-long program for 900 high school students from 16 different schools that presented protective strategies by teachers to promote educational resilience. Students were provided with a self-paced curriculum in which the teacher emphasized caring, support, and high expectations. Additionally, students were encouraged to be engaged and involved. The study found that students completing the program had higher grades than a comparison group at the end of the academic year [47]. Additional strategies to increase educational resilience can be organized into the following clusters: (a) teacher-student rapport, (b) classroom environment, (c) teaching strategies, and (d) student skills [48]. Twelve strategies produced by Downey were organized into the clusters and have been recommended for facilitation in the classroom among all educators.

1.5. Emotional and Behavioral Resilience. Although there is a great deal of literature on educational resilience and teacher support, there is little research that examines the effect of teacher support on other types of resilience. Teacher support can also protect against stressors for youth in nonacademic ways. Emotional and behavioral resilience can be described as the ability to adapt under stress and resist developing emotional and behavioral problems [37]. Moreover, a few studies have shown that teacher support can be a protective factor for emotional and behavioral resilience [31, 36-38]. Similar to research on educational resilience, these studies focus on background characteristics of youth $[31,37]$ and strategies for fostering resilience $[36,38]$.

Research has shown that youth who experience problems with parents may benefit from teacher support, which can ameliorate the negative effects of not receiving support from parents [31]. Gootman [37] explained how teachers who provide empathy, trust, and patience can foster emotional resilience in abused children. Strategies for developing emotional and behavioral resilience have been identified and discussed in the literature [36, 38]. Benard identified three strategies that teachers can model and implement to buffer risk and facilitate positive development in youth. Those include (a) caring relationships, (b) positive and high expectations, and (c) opportunities to participate and contribute. Building a relationship on care and concern, validating feelings, and demonstrating kindness and respect can nurture development and encourage growth in youth [38]. High expectations from educators can structure and guide student behavior and, when provided with the opportunity to participate and contribute, students may feel challenged and successful [38]. Other strategies to promote resilience include instruction of self-monitoring, social skills, and selfreinforcement strategies [36].

The current study examines the amount of support from teachers perceived by youth, rather than the quality or elements of the teacher-student relationship. Inferences could be made about the quality of the teacher-student relationship based on child perceptions of teacher support; however, no measure of the teacher-student relationship was used in the current study. This is consistent with research that suggests perception of support is more important as a protective factor than the actual support received [49].

The purpose of the present study is to examine the effects of teacher support as a protective factor for children exposed to stressful life events. Consistent with previous research, the initial prediction is that children will show more externalizing and internalizing problems when challenged by more stressful life events. Furthermore, it is hypothesized that teacher support will buffer the effects of stressful life events, and that stressed children with more teacher support will display less externalizing and internalizing problem behaviors than stressed children with lower levels of teacher support.

\section{Method}

Data presented in this study was collected as part of a larger study for the Ethics and Resilience Research Lab at Minnesota State University, Mankato. Participants and measures for the current study are described. Additionally, procedures from the larger study are reviewed. The difference between this study and the larger study is the larger study was made up of more questions but not more participants. The same participants were used for the current study as well as the larger study.

2.1. Participants. Participants in the present study included 103 children from a medium-sized midwestern town. Child participants ranged in age from 7 to 15 years old, $(M=$ $10.08, S D=1.92)$. Fifty-two percent of the child participants were girls. The majority of the participants were Caucasian (94.2\%), but also included Native American (1.0\%) and MultiRacial (4.8\%) participants. Household income ranged from $\$ 10,000$ to $\$ 300,000$ annually, with a mean income of $\$ 81,987.75$. 


\subsection{Measures}

2.2.1. Externalizing Problems. Externalizing problems were measured using the Behavior Assessment System for Children, Second Edition (BASC-2; [50]). The BASC-2 Parent Rating Scale (PRS) is a 160 -item questionnaire used to collect information about a child's behavior and personality from the parent's perspective. The BASC-2 PRS has two different forms, which are based on age-appropriate norms. Parents with children 7-11 years of age were given the child form (PRS-C) and parents with children 12-15 years of age were given the adolescent form (PRS-A). Both forms have fourteen primary subscales and four composite subscales. Psychometric properties of the BASC-2 evidence strong reliability and validity. There was superior internal consistency for the externalizing problems composite (Cronbach's $\alpha=$ 0.94 for the PRS-C and PRS-A). There was also high interrater reliability $(r=0.69$ for the PRS-C and $r=0.77$ for the PRS-A). Due to previous research indicating that parent-report is a better measure of externalizing symptoms than child self-report, parent-report was used to assess child's externalizing symptoms [51, 52]. The composite of externalizing problems included subscales of hyperactivity, aggression, and conduct problems.

2.2.2. Internalizing Problems. Internalizing problems were measured using the Behavior Assessment System for Children, Second Edition (BASC-2; [50]). The BASC-2 Self Personality Report (SPR) is a questionnaire used to collect information about a child's behavior and personality from the child or adolescent's perspective. The BASC-2 SPR has two different forms, which are based on age-appropriate norms. Children 8-11 years of age were given the child form (SPR-C) and children 12-15 years of age were given the adolescent form (SPR-A). The SPR-C consists of 139 items, 14 primary subscales, and 5 composite subscales. The SPR-A consists of 176 items, 16 primary subscales, and 5 composite subscales. The self-report of the BASC-2 also has strong reliability and validity. It has high internal reliability for the internalizing problems composite (Cronbach's $\alpha=0.96$ for the SPR-C and SPR-A). Additionally, test-retest reliability is high ( $r=0.71$ for the SPR-C and $r=0.75$ for the SPR-A). Previous research has shown that child self-report provides distinct information about internalizing symptoms that may not be reported by parents [53, 54]. Therefore, child and adolescent self-reports were used to measure internalizing symptoms. The internalizing problems composite includes subscales of atypicality, locus of control, social stress, anxiety, depression, sense of inadequacy, and somatization.

2.2.3. Stressful Life Events. Stressful life events were measured using the Life Events Checklist (LEC; [55]). The LEC is a 48 -item inventory used to gather information about the different types of life stressors that children and adolescents experience. The LEC assess whether specific life stressors occurred in the past year, if they were good or bad, and the degree to which they were good or bad. The degree to which the event was good or bad was rated on a 4 -point scale: $0=$ none (not good or bad at all), $1=$ little (a little bit good or bad), 2 = medium (pretty good or bad), 3 = big (really good or bad). Studies have shown the LEC to have strong validity [55] and reliability [56]. Test retest reliability over a two-week interval was strong for negative events $(r=0.72, P<0.001$; [56]). A score of life stress was calculated by summing the number of events experienced and endorsed as negative. A higher score of life stress would indicate a greater amount of negative life stress experienced.

2.2.4. Teacher Support. Teacher support was measured using the Social Support Scale for Children (SSSC; [57]). The SSSC is a 24-item questionnaire that evaluates different forms and amounts of social support present in a child's life. The SSSC has four subscales, which include child perception of parent, classmate, teacher, and friend support. Teacher support was measured using the teacher support/regard subscale, which includes six items from the questionnaire. These items appraise teacher caring, helping, and fairness. Subscale items are summed and then divided by the number of items to obtain an average score for that subscale. Scores range from 1 to 4 , with a higher score indicating more support. The psychometric properties of the SSSC are strong and dependable. There was good internal consistency for the teacher support subscale (Cronbach's $\alpha=0.81$ for children and Cronbach's $\alpha=0.84$ for adolescents).

2.3. Procedure. Forms were distributed at local schools and extracurricular activities. Children and parents interested in participating in the research filled out forms and left them in secured boxes at schools and local activity locations. Members of the Ethics and Resilience Research Lab collected the completed forms and contacted parents based on their interest. Appointments for data collection were scheduled based on the child and parent interest in the study.

Data collection was conducted at the child's school or in the psychology department at a medium sized midwestern university. Both the child and one parent participated in the data collection. Data were collected in separate rooms for child and parent participants and a research assistant was present in each room with the participants. Parent participants signed an informed consent and child participants signed an assent form.

After signing the consent, parents were instructed to read the directions on each questionnaire (given in randomized order), complete all the items, and direct any questions to the research assistant. For children younger than 12 years of age, the research assistant read the assent form and all items on the questionnaires aloud to the participants. Children 12 years and older were given the assent form and asked to read it aloud to the research assistant. If the child was able to read the assent without difficulty, he or she completed the questionnaires independently. The questionnaires took about 45 minutes for child and parent participants to fill out. Upon completion of all the questionnaires, parent participants were given $\$ 5$ compensation for participation in the study. 
2.4. Statistical Analyses. Moderation analyses were conducted to test for main effects and interactions between life stress and teacher support to determine how these variables predicted behavioral outcomes. Two separate moderation analyses were performed on externalizing and internalizing problems using life stress and teacher support as predictors. A multiple regression was conducted with the criterion and predictors in step one and then with the predictors and an interaction variable created from the predictors, life stress and teacher support, in step two.

\section{Results}

In the first moderation analyses, externalizing problems served as the criterion with life stress and teacher support as predictors. There was a significant main effect for life stress; however, there was not a main effect for teacher support. Additionally, after adding the interaction term to the predictors in step two, there was a significant interaction for life stress and teacher support. Findings provided support for the hypothesis that teacher support would moderate the effects of life stress on externalizing problems. In particular, teacher support was a protective factor against externalizing problems for youth experiencing life stress. Furthermore, these findings were consistent with previous research and the hypothesis that greater amounts of life stress would predict more negative behavioral outcomes in youth, specifically externalizing problems. A second moderation analyses was also performed to investigate externalizing problems as the criterion along with the interaction of predictors, gender and life stress as well as the interaction of gender and teacher support. No significant interaction effects were found. The interactions of income and life stress as well as the interactions of income and teacher support were also analyzed while keeping externalizing behavior as a predictor. No significant interaction effects were found. Findings therefore support the hypothesis that regardless of child gender and family income, teacher support would still moderate the effects of life stress on externalizing behavior. Results of the first moderation analysis are presented in Table 1.

In an additional moderation analysis, internalizing behavior was used as the criterion variable with life stress and teacher support as predictors. There was a main effect for life stress. This also was consistent with the previous literature [58] and the hypothesis that life stress would predict negative emotional and behavioral outcomes, more specifically internalizing problems. On the other hand, there was not a main effect for teacher support, or a significant interaction. Findings from the second analysis did not support the hypothesis that teacher support moderates internalizing problems for youth exposed to stressful life events. A moderation analysis was also performed to investigate internalizing problems as the criterion along with the interaction of predictors; gender and life stress as well as the interaction of gender and teacher support. No significant interaction effects were found. The interactions of income and life stress as well as the interactions of income and teacher support were also analyzed while keeping internalizing behavior as a predictor.
No significant interaction effects were found. Results for the second analysis are presented in Table 2.

\section{Discussion}

The main purpose of the current study was to expand upon previous research by examining teacher support as a moderator of behavioral outcomes for youth with stressful life events. First, main effects will be discussed, followed by the interactions. Implications of results, limitations of the study, and ideas for future direction are also stated.

4.1. Main Effects. Consistent with the previous literature, this study found that life stress predicts emotional and behavioral problems, both externalizing and internalizing [6, 9]. Furthermore, youth who had greater amounts of negative life stress experienced greater externalizing and internalizing problems and youth with less life stress experienced less externalizing and internalizing problems.

There was not a main effect for teacher support. The first possible explanation for these findings is based on different sources of support (e.g., parents, peers, and teachers) and their importance at a range of ages in youth. The previous literature has shown that parent support is the most influential of younger children's social environments and it also is the most predictive of emotional and behavioral outcomes $[16,58]$. As youth age, peer support has proven to be more influential for adolescents $[24,28]$. It is possible that youth have set expectations about teacher support and how teachers relate and interact with them [59]. Due to those set expectations, youth may still perceive teachers as highly supportive, but the support that teachers provide may not buffer externalizing and internalizing problems for youth. Furthermore, teacher support might only be able to buffer externalizing and internalizing problems for youth when they are experiencing stressful life events. For example, youth that experience negative life stress from conflict with family or peers might find teacher support to be more protective against negative outcomes than usual because their primary sources of support may not be effective or might be contributing to the stress. Also, youth who are not stressed might not rely on teacher support.

Additionally, consideration should be given to the restricted response range in the variable of teacher support. Youth rated teachers high on the support scale with scores ranging from 2.17 to 4.00 , and a mean score of 3.64 (SD = 0.42 ). Post hoc analyses revealed the distribution had very significant negative skew $\left(z_{\text {skewness }}=-5.37, P<0.001\right)$ and significant kurtosis $\left(z_{\text {kurtosis }}=3.07, P<0.01\right)$. This indicates that the majority of youth found teachers to be highly supportive and there was limited variability in responding (see Figure 2). Although a higher amount of social support from teachers is desired for all youth and previous research has shown its benefits $[31,36,38]$, a restricted range of scores for teacher support can reduce variance and may fail to reveal main effects [60] and moderating effects [61]. 
TABLE 1: Hierarchical regression—externalizing problems (BASC) as criterion.

\begin{tabular}{|c|c|c|c|c|c|}
\hline Variable & Stand. $\beta$ & Model $R^{2}$ & Model $F$ & $(d f)$ & $\Delta R^{2}$ \\
\hline Step 1: Main effects & & 0.102 & $5.610^{* *}$ & $(2.99)$ & - \\
\hline Life stress & $0.285^{* *}$ & & & & \\
\hline Teacher support & -0.127 & & & & \\
\hline Step 2: Main effects \& interaction & & 0.139 & $5.285^{* *}$ & $(3.98)$ & 0.037 \\
\hline Life stress & $2.268^{*}$ & & & & \\
\hline Teacher support & 0.220 & & & & \\
\hline Life stress $\times$ Teacher & $-2.002 *$ & & & & \\
\hline
\end{tabular}

$* P<0.05,{ }^{* *} P<0.01$.

TABLE 2: Hierarchical regression—internalizing problems (basc) as criterion.

\begin{tabular}{|c|c|c|c|c|c|}
\hline Variable & Stand. $\beta$ & Model $R^{2}$ & Model $F$ & $(d f)$ & $\Delta R^{2}$ \\
\hline Step 1: Main effects & & 0.478 & $43.941^{* *}$ & $(2.96)$ & - \\
\hline Life stress & $0.670^{* *}$ & & & & \\
\hline Teacher support & -0.132 & & & & \\
\hline Step 2: Main effects \& interaction & & 0.487 & $30.063^{* *}$ & $(3.95)$ & 0.009 \\
\hline Life stress & $1.641^{*}$ & & & & \\
\hline Teacher support & 0.037 & & & & \\
\hline Life stress $\times$ Teacher & -0.979 & & & & \\
\hline
\end{tabular}

${ }^{*} P<0.05,{ }^{* *} P<0.01$.

4.2. Interaction. The results partially supported the hypothesis that support from teachers can moderate the effect of life stress on behavioral outcomes. This reinforces the theory that teacher support can help promote emotional and behavioral resilience for children experiencing higher amounts of negative life stress (Figure 1). It was expected that teacher support would significantly moderate both externalizing and internalizing problems; however, a significant interaction was only found for externalizing problems. There may be several possible explanations for why this difference was found.

Externalizing problems in youth may be unique in comparison to internalizing problems when considering topography, detection, and treatment planning. Externalizing behavior problems are more obvious and gain more attention from teachers than internalizing problems [3941]. This could result in more support from teachers geared toward prevention and alleviation of externalizing problems that are disruptive to the classroom and the teaching process. Proactively, behavior intervention plans (BIPs) are being implemented in schools by teachers for youth with externalizing behavior problems. Increasingly, BIPs have been aimed at incorporating behavior management with a supportive environment in a conscious attempt to create student-centered BIPs. Furthermore, educators take a team approach to identify, assess, and generate BIPs to modify externalizing behavior problems [62]. These proactive measures taken by teachers may provide support that is more likely to moderate the effects of externalizing behavior than internalizing behavior for youth experiencing stressful life events.

On the other hand, there is very little research to explain the teacher-student relationship and internalizing problems

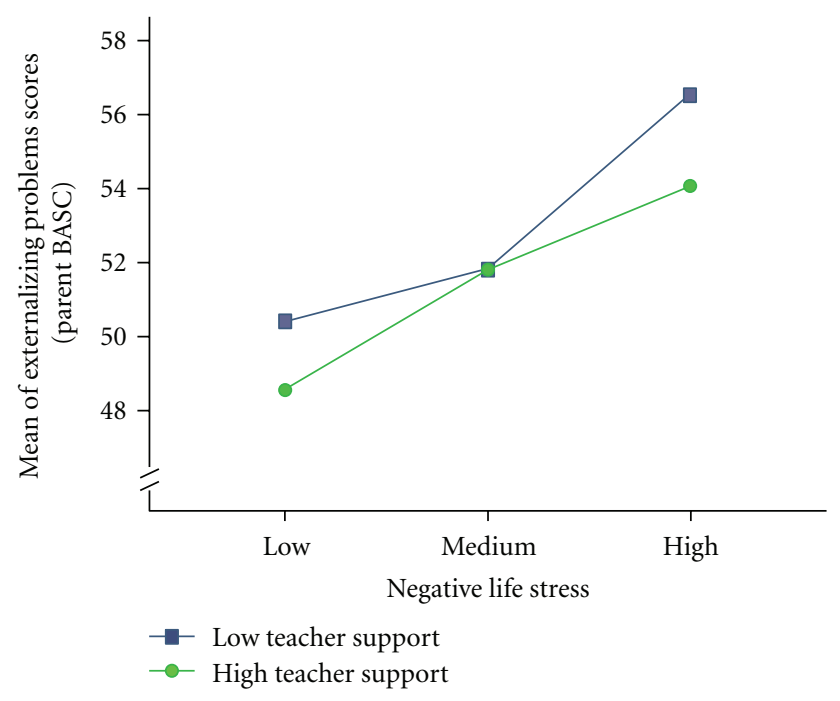

FIGURE 1: Mean externalizing problems composite scores on parent (BASC) as a function of the amount of teacher support and negative life stress experienced.

in youth [39]. Previous research has shown that children with internalizing problems were not as close to their teacher when compared to a normal developing group of their peers. Children with internalizing problems were more likely to be unnoticed by teachers and had more conflict upon social engagement with teachers [41]. Due to the indiscernible outward behavior of internalizing problems in youth, symptoms may be difficult for teachers to identify. It may be possible that teachers were not able to identify internalizing problems in some individuals and, therefore, 


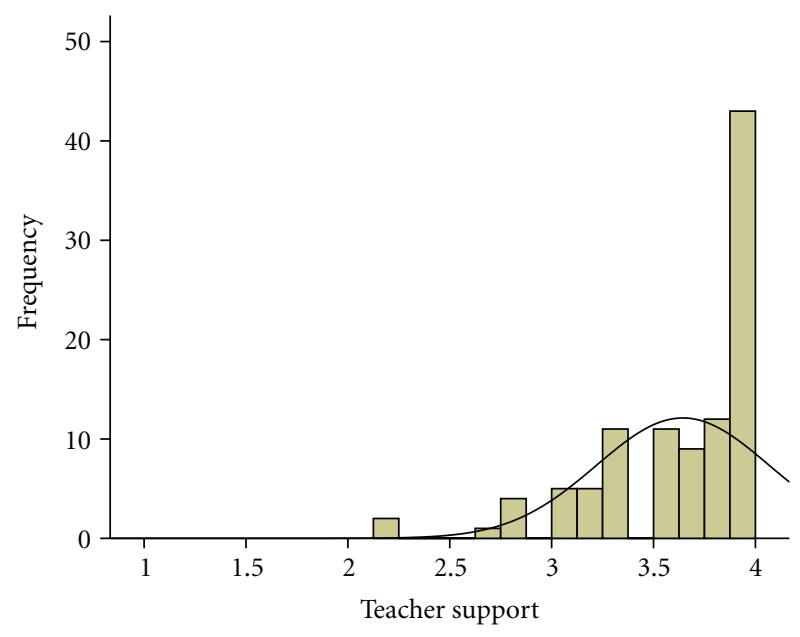

FIgURE 2: Histogram displaying frequencies of the amount of youth-perceived teacher support reported.

did not focus support toward helping those youth with such difficulties.

Youth with internalizing problems tend to have higher levels of depression, anxiety, sense of inadequacy, and limited social skills, which may ultimately lead to conflict or poor social interactions [39]. Teacher support may have failed to moderate internalizing problems for youth experiencing life stress because of difficulty with positive social interactions and forming a quality teacher-student relationship. Positive social interactions are a crucial part of developing a warm and nurturing teacher-student relationship that can influence a child's course of developmental and enhance positive adaptation [40]. If a student is unable to form a caring and trusting teacher-student relationship due to conflict or a lack of social competence, this may increase social stress and contribute to internalizing problems [42]. While this explanation may not fully account for why teacher support failed to moderate the effects of internalizing problems for youth in this study, it is acknowledged that the relationship between teacher support and internalizing problems in youth experiencing stressful life events is complex and requires further investigation.

4.3. Implications. There are several important implications from the study. First, the interaction between stress and teacher support in predicting externalizing behavior supports the hypothesis and previous findings from literature that teacher support moderates the relationship between life stress and negative behavioral outcomes [31]. These results are consistent with the social support theory that youth are able to utilize teachers to their benefit in the presence of stress [23]. Findings suggest teachers can serve an important buffering role to the effects of stress by providing care, concern, fairness, respect, empathy, and challenge to youth [38]. Additionally, these results lend credence to previously mentioned strategies to increase teacher support and promote emotional and behavioral resilience in the classroom [36, 38]. Programs that focus on building caring relationships with students and that include self-monitoring, social skills, and self-reinforcement strategies could foster resilience and should be considered for implementation in the regular curriculum $[36,38]$.

Another important suggestion is for teachers to be alert for students with internalizing behaviors and try to provide those students with more support. Furthermore, training for teachers should be focused on recognizing emotional problems and mental health symptoms so teachers can identify internalizing problems and direct their support to those children. Those students may have difficulty engaging with teachers, and conflict may arise upon interaction [42]. It is necessary for teachers to identify these students and increase social engagements and model appropriate social interactions. Teaching social skills and increasing social competence may play an important role in moderating internalizing symptoms for these individuals $[39,42]$.

The relationship that exists between stress and emotional and behavioral problems was consistent with previous research $[6,9]$. These research findings substantiate the need for programs that address stress management for youth. Educators can help play an important role in stress management by teaching coping skills and introducing youth to healthy ways to reduce and manage stress $[9,16]$. If youth are able to cope successfully with stress from life events, they will be less likely to experience negative emotional and behavioral outcomes [46].

4.4. Limitations. The study has some limitations and results should be interpreted with caution. First, as with many studies from medium-sized midwestern towns, the sample was predominantly Caucasian. The mean family household income for participants in this study was in the seventyfifth percentile when compared to the median distribution of the national income [63]. Youth in the sample did experience stressful life events; however, a great deal of resilience literature focuses on children exposed to different stressors, such as poverty, violence, and crowded schools, which were not studied (or likely) in this project $[5,16,26]$. Due to homogeneity, caution should be used before generalizing these results to populations beyond the demographic constraints of the sample.

4.5. Future Research. Future research should include but not be limited to larger, more diverse samples to increase generalization. Additionally, teacher support could be compared to other protective factors such as parent or peer support and income to determine its importance in buffering the effects of stress for children. Further examination of the relationship between teacher support, age, and gender could also be evaluated to determine if there were differences in separate age and gender categories. Additionally, future research could include use of structural equation modeling to examine the relationship between teacher support, externalizing and internalizing problems, and life stress more in depth.

Integrating data from multiple informants may be beneficial to future research: developing a study that includes teacher-perspective or other objective measures of classroom 
performance could allow for measurement of educational resilience in addition to emotional and behavioral resilience. This would add to the previous literature on educational resilience as well as build on emotional and behavioral resilience research. Furthermore, it could offer suggestions for how the two relate to each other and their relationship to teacher support.

Future research also should include using a measure of teacher support that examines different aspects of the teacher-student relationship. It would be important to understand social competence within the teacher-student relationship and if higher levels of social competence could help buffer internalizing behavior for youth. Also, comparison of teacher and child perspectives of the teacherstudent relationship may provide further insight into the components of teacher support that can moderate stress and negative outcomes for youth. Future work should also seek to examine the relationship between externalizing and internalizing problems, life stress, and teacher support in greater detail. Observation of behavior in the classroom and teacher-student and peer-student social interactions in the classroom may help uncover some of the mystery behind internalizing problems and social support as a protective factor for these youth.

\section{References}

[1] J. H. Humphrey, Childhood Stress in Contemporary Society, The Hawthorne Press, Binghamton, NY, USA, 2004.

[2] N. Garmezy, "Stressors of childhood," in Stress, Coping and Development in Children, N. Garmezy and M. Rutter, Eds., pp. 43-84, McGraw-Hill, New York, NY, USA, 1983.

[3] N. Garmezy and M. Rutter, "Acute reactions to stress," in Child and Adolescent Psychiatry: Modern Approaches, M. Rutter and L. Hersov, Eds., pp. 152-176, Blackwell Scientific, Oxford, UK, 2nd edition, 1985.

[4] K. J. Kim, R. D. Conger, G. H. Elder, and F. O. Lorenz, "Reciprocal influences between stressful life events and adolescent internalizing and externalizing problems," Child Development, vol. 74, no. 1, pp. 127-143, 2003.

[5] S. B. Turkel and S. Eth, "Psychological responses to stress: adjustment disorder and post-traumatic stress disorder in children and adults," in Childhood stress, E. L. Arnold, Ed., pp. 51-71, John Wiley, New York, NY, USA, 1990.

[6] L. E. Arnold, Childhood Stress, John Wiley \& Sons, New York, NY, USA, 1990.

[7] B. E. Compas, B. R. Hinden, and C. A. Gerhardt, "Adolescent development: pathways and processes of risk and resilience," Annual Review of Psychology, vol. 46, pp. 265-293, 1995.

[8] M. Rutter, "Stress, coping, and development: some issues and some questions," in Stress, Coping, and Development in Children, N. Garmezy and M. Rutter, Eds., pp. 1-41, McGrawHill, New York, NY, USA, 1983.

[9] P. V. Trad and E. Greenblatt, "Psychological aspects of child stress: development and the spectrum of coping responses," in Childhood Stress, E. L. Arnold, Ed., pp. 23-49, John Wiley, New York, NY, USA, 1990.

[10] A. L. Baldwin, C. Baldwin, and R. E. Cole, "Stress-resistant families and stress-resistant children," in Risk and Protective Factors in the Development of Psychopathology, J. Rolf, A. S. Masten, D. Cicchetti, K. H. Nuechterlein, and S. Weintraub,
Eds., pp. 257-280, Cambridge University Press, New York, NY, USA, 1990.

[11] E. E. Werner, "Protective factors and individual resilience," in Handbook of Early Childhood Intervention, S. J. Meisels and J. P. Shonkoff, Eds., pp. 97-116, Cambridge University Press, New York, NY, USA, 1990.

[12] P. A. Cowan, C. P. Cowan, and M. S. Schulz, "Thinking about risk and resilience in families," in Stress, Coping, and Resiliency in Children and Families, E. M. Hetherington and E. A. Blechman, Eds., pp. 1-38, Lawrence Erlbaum, Mahwah, NJ, USA, 1996.

[13] N. Garmezy, "Children under stress: perspectives on antecedents and correlates of vulnerability and resistance to psychopathology," in Further Explorations in Personality, A. I. Rabin, J. Aronoff, A. M. Barclay, and R. A. Zucker, Eds., pp. 196-269, John Wiley, Toronto, Canada, 1981.

[14] N. Garmezy and A. Tellegen, "Studies of stress-resistant children: methods, variables, and preliminary findings," in Applied Developmental Psychology, F. J. Morrison, C. Lord, and D. P. Keating, Eds., pp. 231-287, Academic Press, Orlando, Fla, USA, 1984.

[15] C. Kauffman, H. Grunebaum, B. Cohler, and E. Gamer, "Superkids: competent children of psychotic mothers," American Journal of Psychiatry, vol. 136, no. 11, pp. 1398-1402, 1979.

[16] E. E. Werner and R. S. Smith, Vulnerable but Invincible: A Longitudinal Study of Resilient Children and Youth, McGrawHill, New York, NY, USA, 1982.

[17] S. Jain, S. L. Buka, S. V. Subramanian, and B. E. Molnar, "Protective factors for youth exposed to violence: role of developmental assets in building emotional resilience," Youth Violence and Juvenile Justice, vol. 10, no. 1, pp. 107-129, 2012.

[18] M. Rutter, "Psychosocial resilience and protective mechanisms," American Journal of Orthopsychiatry, vol. 57, pp. 316331, 1987.

[19] A. S. Masten, J. J. Cutuli, J. E. Herbers, and M. G. J. Reed, "Resilience in development," in The Oxford Handbook of Positive Psychology, S. J. Lopez and C. R. Snyder, Eds., Oxford University Press, New York, NY, USA, 2009.

[20] S. Kidd, C. C. Henrich, K. A. Brookmeyer, L. Davidson, R. A. King, and G. Shahar, "The social context of adolescent suicide attempts: interactive effects of parent, peer, and school social relations," Suicide and Life-Threatening Behavior, vol. 36, no. 4, pp. 386-395, 2006.

[21] A. S. Masten, "Ordinary magic: resilience processes in development," American Psychologist, vol. 56, no. 3, pp. 227-238, 2001.

[22] W. M. Ensel and N. Lin, "The life stress paradigm and psychological distress," Journal of Health and Social Behavior, vol. 32, no. 4, pp. 321-341, 1991.

[23] R. S. Lazarus and S. Folkman, Stress, Appraisal, and Coping, Springer, New York, NY, USA, 1984.

[24] R. Crosnoe, "Friendships in childhood and adolescence: the life course and new directions," Social Psychology Quarterly, vol. 63, no. 4, pp. 377-391, 2000.

[25] L. Pryor-Brown and E. L. Cowen, "Stressful life events, support, and children's school adjustment," Journal of Child Clinical Psychology, vol. 18, pp. 214-220, 1989.

[26] E. M. Kinard, "Perceived social support and competence in abused children: a longitudinal perspective," Journal of Family Violence, vol. 10, no. 1, pp. 73-98, 1995.

[27] D. Belle, Ed., Children's Social Networks and Social Supports, John Wiley \& Sons, New York, NY, USA, 1989.

[28] T. J. Berndt, "Obtaining support from friends during childhood and adolescence," in Children's Social Networks and 
Social Supports, D. Belle, Ed., pp. 308-331, John Wiley, New York, NY, USA, 1989.

[29] R. Crosnoe and G. H. Elder, "Family dynamics, supportive relationships, and educational resilience during adolescence," Journal of Family Issues, vol. 25, no. 5, pp. 571-602, 2004.

[30] P. R. Smokowski, A. J. Reynolds, and N. Bezruczko, "Resilience and protective factors in adolescence: an autobiographical perspective from disadvantaged youth," Journal of School Psychology, vol. 37, no. 4, pp. 425-448, 1999.

[31] K. T. Call and J. T. Mortimer, Arenas of Comfort in Adolescence: A Study of Adjustment in Context, Lawrence Erlbaum, Mahwah, NJ, USA, 2001.

[32] C. Muller, "The role of caring in the teacher-student relationship for at-risk students," Sociological Inquiry, vol. 71, no. 2, pp. 241-255, 2001.

[33] C. Muller, S. R. Katz, and L. J. Dance, "Investing in teaching and learning: dynamics of the teacher-student relationship from each actor's perspective," Urban Education, vol. 34, no. 3, pp. 292-337, 1999.

[34] S. M. Nettles, W. Mucherah, and D. S. Jones, "Understanding resilience: the role of social resilience," Journal of Education for Students Placed at Risk, vol. 5, pp. 47-60, 2000.

[35] J. L. Split, J. N. Hughes, J. Y. Wu, and O. M. Kwok, "Dynamics of teacher-student relationships: stability and change across elementary school and the influence on children's academic success," Child Development, vol. 83, no. 4, pp. 1180-1195, 2012.

[36] M. A. Bruce, "Fostering resiliency in students: positive action strategies for classroom teachers," The Teacher Educator, vol. 31, pp. 178-188, 1995.

[37] M. E. -Gootman, "Child abuse and its implications for early childhood educators," Preventing School Failure, vol. 40, pp. 149-153, 1996.

[38] B. Benard, "Turning it around for all youth: from risk to resilience," ERIC/CUE Digest 126, ERIC Clearinghouse on Urban Education, New York, NY, USA, 1997.

[39] J. A. Baker, S. Grant, and L. Morlock, "The teacher-student relationship as a developmental context for children with internalizing and externalizing behavior problems," School Psychology Quarterly, vol. 23, pp. 3-15, 2008.

[40] B. K. Hamre and R. C. Pianta, "Early teacher-child relationships and the trajectory of children's school outcomes through eighth grade," Child Development, vol. 72, no. 2, pp. 625-638, 2001.

[41] L. Henricsson and A. M. Rydell, "Elementary school children with behavior problems: teacher-child relations and selfperception. A prospective study," Merrill-Palmer Quarterly, vol. 50, no. 2, pp. 111-138, 2004.

[42] C. E. Hamilton, C. Howes, and R. C. Pianta, "A comparison of young children's relationships with mothers and teachers," in New Directions for Child Development, vol. 57 of Beyond the Parent: The Role of other Adults in Children's Lives, pp. 41-59, Jossey-Bass Inc, San Francisco, Calif, USA, 1992.

[43] R. C. Pianta, Enhancing Relationships between Children and Teachers, American Psychological Association, Washington, DC, USA, 1992.

[44] M. Wang, G. Haertel, and H. Walberg, Educational resilience, National Research Center on Education in the Inner Cities, Philadelphia, Pa, USA, 1998.

[45] W. Franklin, "Students at promise and resilient: a historical look at risk," in Schooling Students Placed at Risk: Research, Policy, and Practice in the Education of Poor and Minority Adolescents, M. G. Sanders, Ed., pp. 3-16, Lawrence Erlbaum, Mahwah, NJ, USA, 2000.
[46] S. S. Luthar, D. Cicchetti, and B. Becker, "The construct of resilience: a critical evaluation and guidelines for future work," Child Development, vol. 71, no. 3, pp. 543-562, 2000.

[47] C. McClendon, S. M. Nettles, and A. Wigfield, "Fostering resilience in high school classrooms: a study of the PASS Program (Promoting Achievement in School Through Support)," in Schooling Students Placed at Risk: Research, Policy, and Practice in the Education of Poor and Minority Adolescents, M. G. Sanders, Ed., pp. 289-307, Lawrence Erlbaum, Mahwah, NJ, USA, 2000.

[48] J. A. Downey, "Recommendations for fostering educational resilience in the classroom," Preventing School Failure, vol. 53, pp. 56-64, 2008.

[49] W. Furman and D. Buhrmester, "Children's perceptions of the personal relationships in their social networks," Developmental Psychology, vol. 21, no. 6, pp. 1016-1024, 1985.

[50] C. R. Reynolds and R. W. Kamphaus, Behavior Assessment System for Children Manual, AGS Publishing, Circle Pines, Minn, USA, 2nd edition, 2004.

[51] T. M. Achenbach, S. H. McConaughy, and C. T. Howell, "Child/Adolescent behavioral and emotional problems: implications of cross-informant correlations for situational specificity," Psychological Bulletin, vol. 101, no. 2, pp. 213-232, 1987.

[52] C. Stanger and M. Lewis, "Agreement among parents, teachers, and children on internalizing and externalizing behavior problems," Journal of Clinical Child Psychology, vol. 22, pp. 107-115, 1993.

[53] C. DiStefano, R. W. Kamphaus, A. M. Horne, and A. P. Winsor, "Behavioral adjustment in the U.S. Elementary school: crossvalidation of a person-oriented typology of risk," Journal of Psychoeducational Assessment, vol. 21, no. 4, pp. 338-357, 2003.

[54] M. M. Moretti, S. Fine, G. Haley, and K. Marriage, "Childhood and adolescent depression: child-report versus parent-report information," Journal of the American Academy of Child Psychiatry, vol. 24, no. 3, pp. 298-302, 1985.

[55] J. H. Johnson and S. M. McCutcheon, "Assessing life stress in older children and adolescents: preliminary findings with the Life Events Checklist," in Stress and Anxiety, I. G. Sarason and C. D. Speilberger, Eds., pp. 230-241, Hemisphere, Washington, DC, USA, 1980.

[56] A. H. Brand and J. H. Johnson, "Note on reliability of the Life Events Checklist," Psychological Reports, vol. 50, p. 1274, 1982.

[57] S. Harter, Manual for the Social Support Scale for Children, University of Denver, Denver, Colo, USA, 1985.

[58] S. S. Luthar and A. Goldstein, "Children's exposure to community violence: implications for understanding risk and resilience," Journal of Clinical Child and Adolescent Psychology, vol. 33, no. 3, pp. 499-505, 2004.

[59] K. G. Fernandez, "Anxiety in adolescents: investigating how cognitive motivations and social support relate with anxious symptomology," Loyola Schools Review, vol. 6, pp. 39-61, 2007.

[60] R. M. Baron and D. A. Kenny, "The moderator-mediator variable distinction in social psychological research: conceptual, strategic, and statistical considerations," Journal of Personality and Social Psychology, vol. 51, pp. 1173-1182, 1986.

[61] H. Aguinis and E. F. Stone-Romero, "Methodological artifacts in moderated multiple regression and their effects on statistical power," Journal of Applied Psychology, vol. 82, no. 1, pp. 192-205, 1997.

[62] S. D. Kroeger and L. J. Phillips, "Positive behavior support assessment guide: creating student-centered behavior plans," 
Assessment for Effective Intervention, vol. 32, pp. 100-112, 2007.

[63] U.S. Census Bureau. (2007, August 28). Current population survey, 2007 annual social and economic supplement, Retrieved February 25, 2009, http://pubdb3.census.gov/ macro/032007/hhinc/toc.htm. 


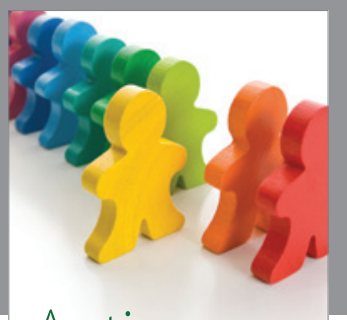

Autism

Research and Treatment
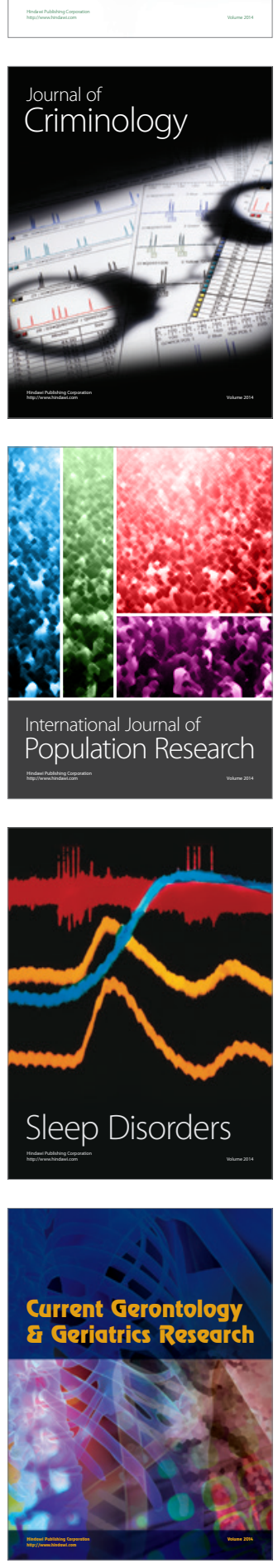
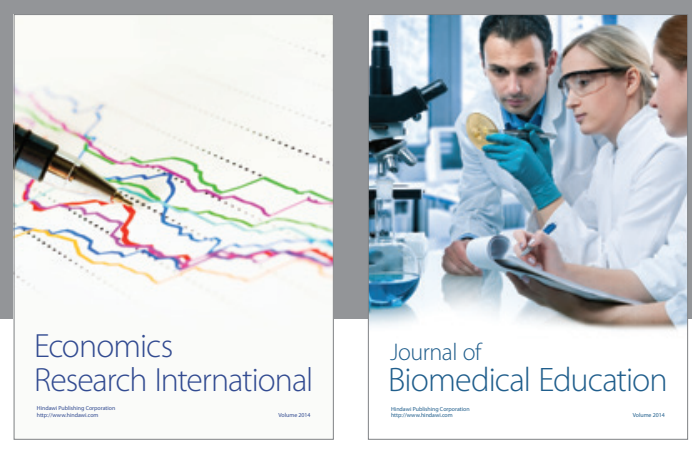

Journal of

Biomedical Education

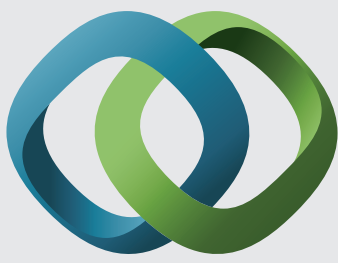

\section{Hindawi}

Submit your manuscripts at

http://www.hindawi.com
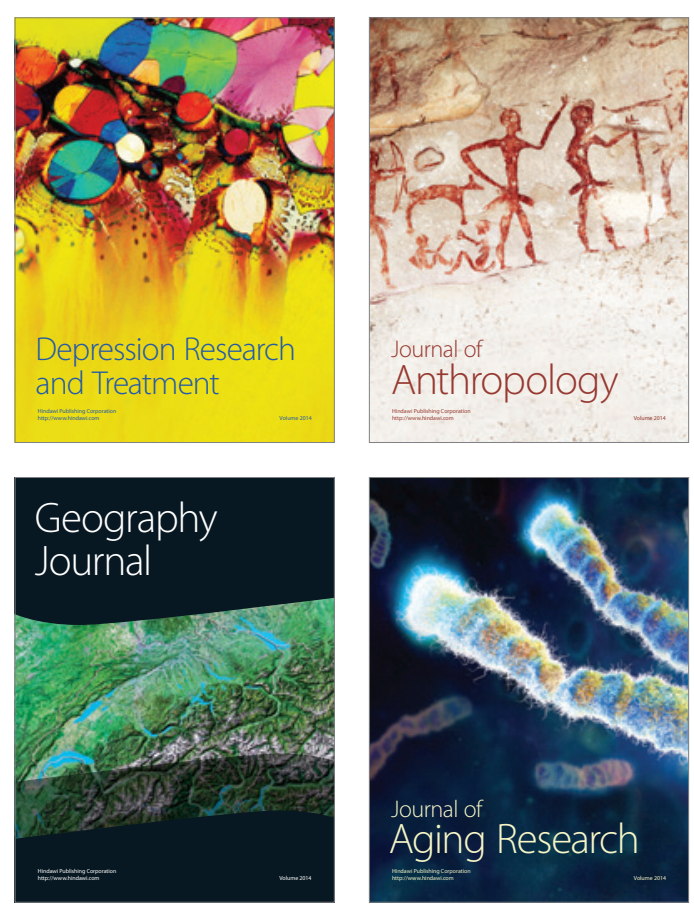

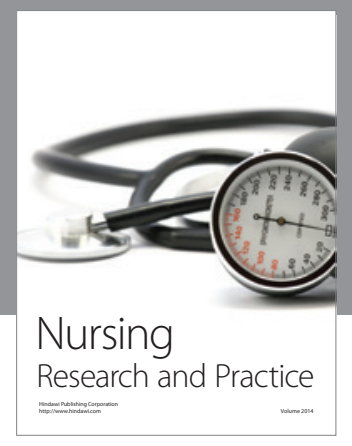

Nursing

Research and Practice

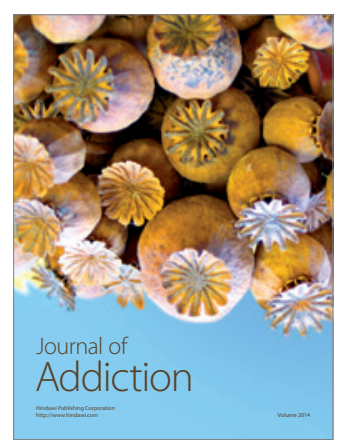

Child Development

Research

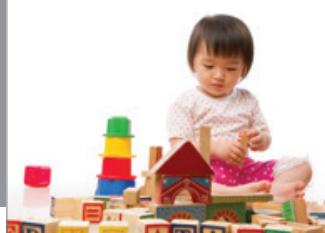

迥
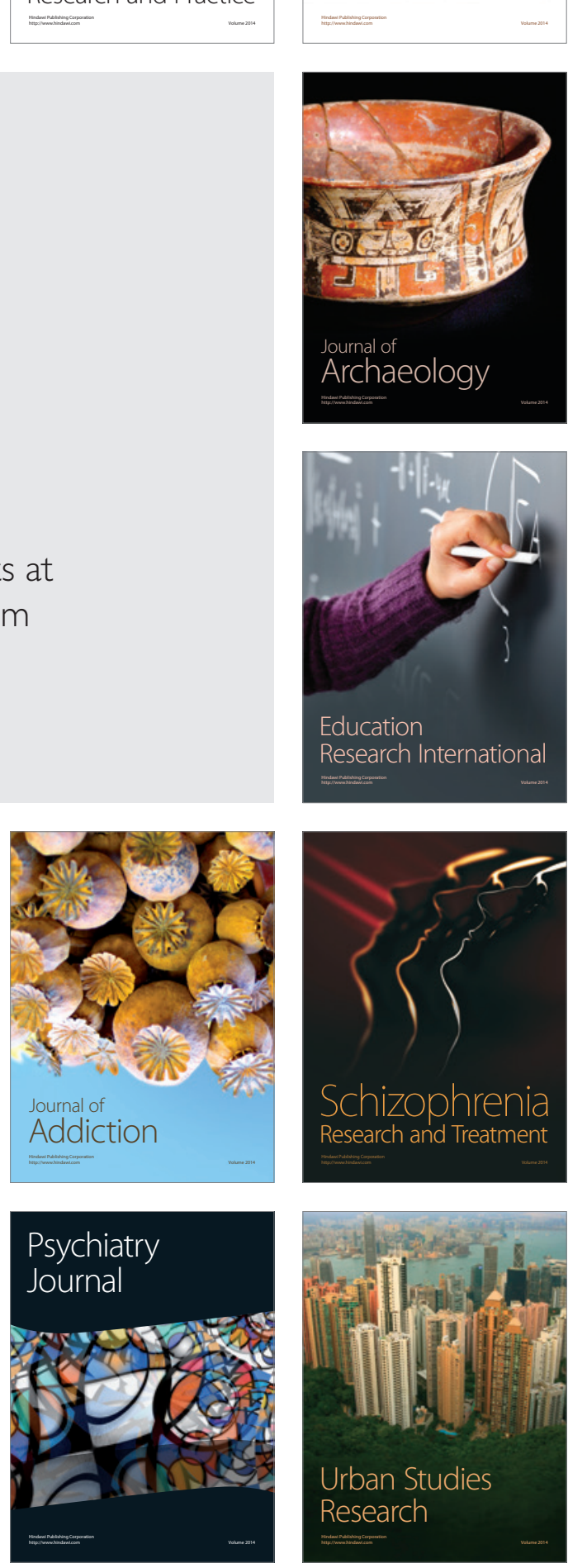